\title{
Body mass index, waist circumference and waist-to-hip ratio cut-off points for categorisation of obesity among Omani Arabs
}

\author{
Jawad A Al-Lawati, ${ }^{1, *}$ and Pekka Jousilahti ${ }^{2,3}$ \\ 'Department of Non-communicable Diseases Surveillance \& Control, PO Box 393, Muscat 113, Ministry of \\ Health, Oman: ${ }^{2}$ Department of Health Promotion and Chronic Disease Prevention, National Public Health \\ Institute, Helsinki, Finland: ${ }^{3}$ School of Public Health, University of Tampere, Tampere, Finland
}

Submitted 12 December 2006: Accepted 21 February 2007: First published online 18 June 2007

\begin{abstract}
Background: There are no data on optimal cut-off points to classify obesity among Omani Arabs. The existing cut-off points were obtained from studies of European populations.

Objective: To determine gender-specific optimal cut-off points for body mass index (BMI), waist circumference (WC) and waist-to-hip ratio (WHR) associated with elevated prevalent cardiovascular disease (CVD) risk among Omani Arabs. Design: A community-based cross-sectional study.

Setting: The survey was conducted in the city of Nizwa in Oman in 2001.

Subjects and methods: The study contained a probabilistic random sample of 1421 adults aged $\geq 20$ years. Prevalent CVD risk was defined as the presence of at least two of the following three risk factors: hyperglycaemia, hypertension and dyslipidaemia. Logistic regression and receiver-operating characteristic (ROC) curve analyses were used to determine optimal cut-off points for BMI, WC and WHR in relation to the area under the curve (AUC), sensitivity and specificity.

Results: Over $87 \%$ of Omanis had at least one CVD risk factor (38\% had hyperglycaemia, $19 \%$ hypertension and 34.5\% had high total cholesterol). All three indices including BMI $(\mathrm{AUC}=0.766)$, WC $(\mathrm{AUC}=0.772)$ and $\mathrm{WHR}(\mathrm{AUC}=0.767)$ predicted prevalent CVD risk factors equally well. The optimal cut-off points for men and women respectively were 23.2 and $26.8 \mathrm{~kg} \mathrm{~m}^{-2}$ for BMI, 80.0 and $84.5 \mathrm{~cm}$ for WC, and 0.91 and 0.91 for WHR.

Conclusions: To identify Omani subjects of Arab ethnicity at high risk of CVD, cutoff points lower than currently recommended for BMI, WC and WHR are needed for men while higher cut-off points are suggested for women.
\end{abstract}

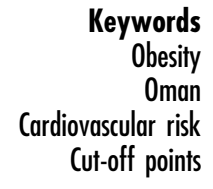

Overweight and obesity are components of a defined cluster of risk factors for non-communicable diseases now observed in both developed and developing countries. Major co-morbidities associated with these conditions include cardiovascular disease (CVD), cerebrovascular disease, type 2 diabetes mellitus, atherogenic dyslipidaemia and certain types of cancer ${ }^{1}$.

Several anthropometric measures have been used to assess abnormal body fat distribution, including body mass index (BMI; weight in kilograms divided by the square of height in metres), waist circumference (WC) and waist-to-hip ratio (WHR). The World Health Organization (WHO) defines overweight as BMI $\geq 25 \mathrm{~kg} \mathrm{~m}^{-2}$, obesity as $\mathrm{BMI} \geq 30 \mathrm{~kg} \mathrm{~m}^{-2}$, and central adiposity as $\mathrm{WC} \geq 94 \mathrm{~cm}$ for men and $\geq 80 \mathrm{~cm}$ for women, and WHR of $\geq 0.90$ in men and $\geq 0.85$ in women ${ }^{2}$. However, such recommendations are derived mainly from data obtained in Western populations. In Asian populations, morbidity and mortality appear to occur at lower BMI and smaller WC values, ${ }^{3}$, with an increasing number of studies showing that the current cut-off points may need to be lowered for non-Caucasian ethnic groups ${ }^{4,5}$.

The unavailability of specific cut-off points for Arab populations of the Middle East has led the International Diabetes Federation (IDF) to recommend that researchers from this region use European cut-off points for WC measurements for both genders until more ethnic-specific data are available for Arabs ${ }^{6}$. Thus, the present study aims to investigate whether BMI, WC or WHR is a better predictor of current CVD risk among Omani Arabs, and to determine optimal cut-off points that could be used for all three parameters to characterise individuals' obesity status in relation to their current CVD risk level. 


\section{Subjects and methods}

We used data from a cross-sectional survey conducted in the city of Nizwa during the initial phase of the Healthy Lifestyle Project in 2001. Nizwa is a city with a population of about 70000 that is located $160 \mathrm{~km}$ south of the capital city, Muscat. Unlike other parts of Oman which are inhibited by populations of multiple ethnicities, Nizwa is inhibited mostly by tribes of Arab ethnicity.

Details of the sampling schemes for the survey have been described elsewhere ${ }^{7}$. In summary, 2000 subjects were invited to participate in the baseline survey of this project and 1421 had complete data on all variables used in this analysis after excluding pregnant women and subjects below 20 years of age. The study protocol was seen and approved by the central ethics committee and informed consent was given by study subjects. The overall response rate was $75.5 \%$ ( $80.3 \%$ in women and $70.8 \%$ in men).

Subjects were asked to fast for $8-14 \mathrm{~h}$ before appearing for an interview to obtain behavioural risk factors, medical history, clinical examination and venous blood samples. To identify prevalent diabetes, a standard oral glucose tolerance test (OGTT) with glucose load of $75 \mathrm{~g}$, as recommended by the WHO, was employed ${ }^{2}$. Individuals who reported diabetes and used antidiabetic medicines were excluded from the OGTT. Individuals with diabetes and on diet control were administered an OGTT. Fasting plasma glucose (FPG) and glucose concentration $2 \mathrm{~h}$ after ingestion of the glucose load $(2 \mathrm{hG})$ were determined by the glucose oxidase method. Serum triglycerides (TG) were measured enzymatically after hydrolysis of glycerol. High-density lipoprotein cholesterol (HDL-C) was measured following the precipitation of other lipoproteins with heparin-manganese chloride mixture. All biochemical analyses were performed using enzymatic reagents from Roche with a Roche/Hitachi 911E analyser according to the specifications of the manufacturer.

Blood pressure was measured to the nearest $2 \mathrm{mmHg}$ on the right arm with the subject seated and having resting for at least $10 \mathrm{~min}$, using a standard mercury sphygmomanometer. The mean of the two readings was taken as the individual's blood pressure. WC was measured twice, with the subject wearing light clothing (underwear), at a level midway between the lower rib margin and the iliac crest, to the nearest $\mathrm{cm}$ using a plastic, non-stretchable tailor's measuring tape. The same procedure was applied for men and women. In addition, weight (in $\mathrm{kg}$ ) and height (in $\mathrm{m}$ ) were also measured, and BMI was calculated.

Individuals were considered to have CVD risk if they had at least two of the following three components:

- Hyperglycaemia - FPG $\geq 5.6 \mathrm{mmoll}^{-1}$ or $2 \mathrm{hG}$ $\geq 11.1 \mathrm{mmol}^{-1}$ or on treatment for diabetes mellitus ${ }^{6,8}$;

- Hypertension - systolic blood pressure (SBP) $\geq 130 \mathrm{mmHg}$ and/or diastolic blood pressure (DBP) $\geq 85 \mathrm{mmHg}$ or on treatment for hypertension ${ }^{6}$;
- Dyslipidaemia - total cholesterol (TC) $\geq 5.2 \mathrm{mmoll}^{-1}$, serum TG $\geq 1.69 \mathrm{mmoll}^{-1}$, low HDL-C $\left(<1.03 \mathrm{mmol}^{-1}\right.$ in men and $1.29 \mathrm{mmoll}^{-1}$ in women) or being on treatment for dyslipidaemia ${ }^{6}$.

Backward stepwise logistic regression analysis was performed using prevalent CVD risk as a dependent factor and age, gender, smoking status at the time of the survey (yes/no), physical activity at leisure time and/or at work (yes/no), and one anthropometric variable (BMI, WC or WHR) at a time as independent covariates. For comparison of the three indices, the regression-fitted values were used to plot receiver-operating characteristic (ROC) curves with sensitivity plotted on the $y$-axis against (1-specificity) on the $x$-axis, and comparing the area under the curve (AUC). The larger the AUC the more accurate the test; an associated $P$-value $<0.05$ was considered statistically significant.

To determine the best cut-off points for BMI, WC and WHR (the shortest distance between any point on the curve and the top left corner on the $y$-axis), separate ROC curves were plotted for each variable and the associated AUC, sensitivity and specificity were determined.

\section{Results}

Of the 1421 participants with complete data in the survey, $725(51 \%)$ were females. The mean ( \pm standard deviation) age of the participants was $38.2 \pm 15.4$ years. Men had higher overall mean SBP and DBP, FPG and TG levels across all categories of BMI, WC and WHR, whereas women had significantly higher mean HDL-C (Table 1). The overall prevalence of CVD risk factors used as outcomes across the three anthropometric measures of obesity is shown in Table 2. Dyslipidaemia and fasting hyperglycaemia were the most highly prevalent risk factors among both genders. The prevalence of systolic, diastolic and overall hypertension was higher in men compared with women. Nearly three out of four Omanis had low levels of HDL-C, one in three had elevated TC, and one in four men had elevated serum TG. Threequarters of women were physically inactive. Smoking was prevalent only among men (9.6\%).

Table 3 shows the distribution of CVD risk factors by gender and age group. Over $87 \%$ of individuals had at least one risk factor, $47 \%$ had at least two risk factors and over $11 \%$ had all three CVD risk factors. Young individuals were more likely to have either one or two risk factors, while subjects in older age groups were more likely to have a constellation of all three risk factors.

Logistic regression analysis showed age, sex and BMI, WC or WHR as significant variables. Physical activity and smoking did not reach significance level and thus were excluded from the analysis. Figure 1 shows ROC curves for regression-fitted values for BMI, WC and WHR in predicting current CVD risk factors. All three 
Table 1 Cardiovascular disease risk factors in the Omani population by categories of body mass index (BMI), waist circumference (WC), waist-to-hip ratio (WHR) and gender; Nizwa survey, 2001

\begin{tabular}{|c|c|c|c|c|c|c|c|c|}
\hline & \multirow[b]{2}{*}{ Overall } & \multicolumn{3}{|c|}{$\mathrm{BMI}\left(\mathrm{kg} \mathrm{m}^{-2}\right)$} & \multicolumn{2}{|c|}{$W^{*}$} & \multicolumn{2}{|c|}{ WHRt } \\
\hline & & $<25.0$ & $25.0-29.9$ & $\geq 30.0$ & Normal & High & Normal & High \\
\hline \multicolumn{9}{|l|}{ Males $(n=696)$} \\
\hline $\mathrm{SBP}(\mathrm{mmHg})$ & $116.6 \pm 17.1$ & $115.6 \pm 16.2$ & $116.0 \pm 17.5$ & $125.2 \pm 19.9$ & $115.3 \pm 15.7$ & $123.2 \pm 22.2$ & $114.5 \pm 15.0$ & $119.0 \pm 19.1$ \\
\hline DBP (mmHg) & $76.2 \pm 8.8$ & $74.5 \pm 7.8$ & $77.5 \pm 9.3$ & $82.4 \pm 9.6$ & $75.2 \pm 8.0$ & $81.2 \pm 11.0$ & $74.3 \pm 7.8$ & $78.3 \pm 9.4$ \\
\hline FPG $\left(\mathrm{mmoll}^{-1}\right)$ & $5.9 \pm 1.6$ & $5.7 \pm 1.4$ & $6.0 \pm 1.8$ & $6.3 \pm 2.1$ & $5.7 \pm 1.3$ & $6.6 \pm 2.4$ & $5.5 \pm 0.9$ & $6.3 \pm 2.1$ \\
\hline $2 \mathrm{hG}\left(\mathrm{mmoll}^{-1}\right)$ & $7.1 \pm 3.0$ & $7.6 \pm 9.4$ & $8.6 \pm 10.1$ & $12.7 \pm 20.7$ & $7.8 \pm 9.7$ & $11.4 \pm 16.5$ & $7.1 \pm 9.2$ & $9.8 \pm 12.9$ \\
\hline $\mathrm{TC}\left(\mathrm{mmoll}^{-1}\right)$ & $4.8 \pm 1.0$ & $4.6 \pm 1.1$ & $5.1 \pm 1.0$ & $5.4 \pm 0.8$ & $4.7 \pm 1.1$ & $5.4 \pm 1.0$ & $4.4 \pm 1.0$ & $5.2 \pm 1.0$ \\
\hline HDL-C $\left(\mathrm{mmol}^{-1}\right)$ & $0.93 \pm 0.2$ & $1.0 \pm 0.2$ & $0.9 \pm 0.2$ & $0.9 \pm 0.3$ & $0.9 \pm 0.2$ & $0.9 \pm 0.3$ & $1.0 \pm 0.2$ & $0.9 \pm 0.2$ \\
\hline $\mathrm{TG}\left(\mathrm{mmoll} \mathrm{I}^{-1}\right)$ & $1.3 \pm 0.9$ & $1.1 \pm 0.7$ & $1.6 \pm 1.1$ & $1.7 \pm 1.0$ & $1.2 \pm 0.8$ & $1.8 \pm 1.3$ & $1.1 \pm 0.7$ & $1.6 \pm 1.1$ \\
\hline \multicolumn{9}{|l|}{ Females $(n=725)$} \\
\hline $\mathrm{SBP}(\mathrm{mmHg})$ & $113.5 \pm 12.1$ & $112.0 \pm 10.9$ & $112.0 \pm 13.2$ & $118.8 \pm 12.9$ & $110.4 \pm 9.9$ & $115.0 \pm 13.0$ & $109.9 \pm 9.2$ & $116.0 \pm 13.2$ \\
\hline $\mathrm{DBP}(\mathrm{mmHg})$ & $71.8 \pm 8.1$ & $70.7 \pm 7.5$ & $71.6 \pm 8.4$ & $75.9 \pm 8.6$ & $69.6 \pm 7.3$ & $73.3 \pm 8.3$ & $69.1 \pm 7.2$ & $73.7 \pm 8.2$ \\
\hline $\mathrm{FPG}\left(\mathrm{mmol} \mathrm{l}^{-1}\right)$ & $5.6 \pm 1.6$ & $5.4 \pm 1.0$ & $5.8 \pm 1.7$ & $6.4 \pm 2.6$ & $5.2 \pm 0.6$ & $6.0 \pm 1.9$ & $5.2 \pm 0.6$ & $6.0 \pm 1.9$ \\
\hline $2 \mathrm{hG}\left(\mathrm{mmoll}^{-1}\right)$ & $7.2 \pm 2.8$ & $7.3 \pm 7.9$ & $10.3 \pm 17.1$ & $10.1 \pm 13.6$ & $6.6 \pm 5.1$ & $9.7 \pm 14.6$ & $6.7 \pm 5.1$ & $9.8 \pm 14.9$ \\
\hline $\mathrm{TC}\left(\mathrm{mmoll}^{-1}\right)^{\prime}$ & $4.9 \pm 1.2$ & $4.7 \pm 1.1$ & $5.2 \pm 1.3$ & $5.3 \pm 1.0$ & $4.4 \pm 0.9$ & $5.3 \pm 1.2$ & $4.4 \pm 0.9$ & $5.3 \pm 1.2$ \\
\hline HDL-C (mmoll $\left.{ }^{-1}\right)$ & $1.2 \pm 0.3$ & $1.2 \pm 0.3$ & $1.2 \pm 0.3$ & $1.1 \pm 0.3$ & $1.2 \pm 0.3$ & $1.1 \pm 0.3$ & $1.2 \pm 0.3$ & $1.1 \pm 0.3$ \\
\hline $\mathrm{TG}\left(\mathrm{mmoll}^{-1}\right)$ & $0.91 \pm 0.7$ & $0.8 \pm 0.5$ & $1.0 \pm 0.7$ & $1.3 \pm 0.9$ & $0.6 \pm 0.4$ & $1.1 \pm 0.8$ & $0.6 \pm 0.4$ & $1.1 \pm 0.8$ \\
\hline
\end{tabular}

SBP, systolic blood pressure; DBP, diastolic blood pressure; FPG, fasting plasma glucose; 2-hG, glucose concentration $2 \mathrm{~h}$ after $75-\mathrm{g}$ oral glucose tolerance test; TC, total cholesterol; HDL-C, high-density lipoprotein cholesterol; TG, triglycerides.

Values are mean \pm standard deviation.

* $W C$ - normal $<94 \mathrm{~cm}$, high $\geq 94 \mathrm{~cm}$ for men; normal $<80 \mathrm{~cm}$, high $\geq 80 \mathrm{~cm}$ for women.

+ WHR - normal $<0.90$, high $\geq 0.90$ for men; normal $<0.85$, high $\geq 0.85$ for women.

Table 2 Prevalence (\%) of cardiovascular disease risk factors in the Omani population by categories of body mass index (BMI), waist circumference (WC), waist-to-hip ratio (WHR) and gender; Nizwa survey, 2001

\begin{tabular}{|c|c|c|c|c|c|c|c|c|}
\hline & \multirow[b]{2}{*}{ Overall } & \multicolumn{3}{|c|}{ BMI $\left(\mathrm{kg} \mathrm{m}^{-2}\right)$} & \multicolumn{2}{|c|}{$W C^{*}$} & \multicolumn{2}{|c|}{ WHRt } \\
\hline & & $<25.0$ & $25.0-29.9$ & $\geq 30.0$ & Normal & High & Normal & High \\
\hline \multicolumn{9}{|l|}{ Males $(n=696)$} \\
\hline $\mathrm{SBP} \geq 130 \mathrm{mmHg}$ & 20.1 & 17.0 & 19.6 & 37.7 & 18.8 & 30.1 & 13.9 & 27.2 \\
\hline $\mathrm{DBP} \geq 85 \mathrm{mmHg}$ & 12.8 & 8.1 & 14.7 & 37.7 & 9.6 & 29.2 & 7.0 & 19.5 \\
\hline Hypertension¥ & 24.7 & 20.2 & 26.7 & 47.5 & 21.8 & 39.8 & 16.4 & 34.4 \\
\hline $\mathrm{FPG} \geq 5.6 \mathrm{mmol}^{-1}$ & 43.0 & 37.6 & 48.9 & 57.4 & 38.8 & 64.4 & 32.7 & 54.8 \\
\hline $2 \mathrm{hG} \geq 11.1 \mathrm{mmolI}^{-1}$ & 11.1 & 8.3 & 12.9 & 23.0 & 8.1 & 26.5 & 4.0 & 19.2 \\
\hline Diabetes mellitus & 12.9 & 9.8 & 15.1 & 26.2 & 9.8 & 29.2 & 4.8 & 22.3 \\
\hline $\mathrm{TC} \geq 5.2 \mathrm{mmoll}^{-1}$ & 34.5 & 24.4 & 46.2 & 59.0 & 30.4 & 55.8 & 19.3 & 52.0 \\
\hline Low HDL-C & 75.9 & 70.2 & 83.6 & 85.3 & 74.1 & 85.0 & 72.4 & 79.9 \\
\hline $\mathrm{TG} \geq 1.7 \mathrm{mmolI}^{-1}$ & 24.4 & 14.9 & 36.4 & 44.3 & 20.4 & 45.1 & 15.5 & 35.9 \\
\hline Physical inactivity\| & 24.3 & 24.6 & 21.5 & 32.8 & 22.7 & 33.0 & 21.1 & 28.0 \\
\hline Current smoking & 9.6 & 10.7 & 7.6 & 9.8 & 10.0 & 8.0 & 10.7 & 8.3 \\
\hline \multicolumn{9}{|l|}{ Females $(n=725)$} \\
\hline $\mathrm{SBP} \geq 130 \mathrm{mmHg}$ & 9.9 & 6.9 & 12.5 & 17.1 & 3.5 & 14.2 & 3.0 & 14.9 \\
\hline $\mathrm{DBP} \geq 85 \mathrm{mmHg}$ & 6.2 & 3.1 & 6.6 & 16.3 & 1.4 & 9.4 & 0.7 & 10.2 \\
\hline Hypertension¥ & 13.8 & 9.5 & 16.0 & 25.2 & 4.9 & 19.6 & 4.0 & 20.8 \\
\hline $\mathrm{FPG} \geq 5.6 \mathrm{mmol}^{-1}$ & 30.8 & 24.7 & 32.6 & 48.8 & 16.4 & 40.2 & 15.9 & 41.4 \\
\hline $2 \mathrm{hG} \geq 11.1 \mathrm{mmolI}^{-1}$ & 11.3 & 5.5 & 14.9 & 26.0 & 2.1 & 17.4 & 2.0 & 18.0 \\
\hline Diabetes mellitus $\$$ & 11.9 & 5.9 & 15.5 & 26.8 & 16.4 & 2.4 & 2.3 & 18.7 \\
\hline $\mathrm{TC} \geq 5.2 \mathrm{mmoll}^{-1}$ & 34.5 & 25.4 & 44.8 & 50.4 & 15.0 & 47.3 & 14.9 & 48.5 \\
\hline Low HDL-C & 71.6 & 67.5 & 71.3 & 86.2 & 63.4 & 76.9 & 66.2 & 75.4 \\
\hline $\mathrm{TG} \geq 1.7 \mathrm{mmoll}^{-1}$ & 13.0 & 9.3 & 16.6 & 20.3 & 4.9 & 18.3 & 5.6 & 18.2 \\
\hline Physical inactivity\| & 69.3 & 70.6 & 66.3 & 68.9 & 64.2 & 27.5 & 61.8 & 25.4 \\
\hline Current smoking & 0.0 & 0.0 & 0.0 & 0.0 & 0.0 & 0.0 & 0.0 & 0.0 \\
\hline
\end{tabular}

SBP, systolic blood pressure; DBP, diastolic blood pressure; FPG, fasting plasma glucose; 2-hG, glucose concentration $2 \mathrm{~h}$ after 75 -g oral glucose tolerance test; TC, total cholesterol; HDL-C, high-density lipoprotein cholesterol; TG, triglycerides.

${ }^{*} W C$ - normal $<94 \mathrm{~cm}$, high $\geq 94 \mathrm{~cm}$ for men; normal $<80 \mathrm{~cm}$, high $\geq 80 \mathrm{~cm}$ for women.

+ WHR - normal $<0.90$, high $\geq 0.90$ for men; normal $<0.85$, high $\geq 0.85$ for women.

$\ddagger$ Hypertension - SBP $\geq 130 \mathrm{mmHg}$ and/or DBP $\geq 85 \mathrm{mmHg}$ or on treatment for hypertension.

\$Diabetes mellitus - FPG $\geq 7.0 \mathrm{mmol}^{-1}$ and/or $2 \mathrm{hG} \geq 11.1 \mathrm{mmol}^{-1}$, or on treatment for diabetes mellitus.

"Low HDL-C $-<1.03 \mathrm{mmoll}^{-1}$ in males and $<1.29 \mathrm{mmoll}^{-1}$ in females.

$\|$ Physical inactivity - inactivity at leisure time and/or at work (yes/no).

indices predicted prevalent CVD risk equally well. The AUC $(95 \%$ confidence interval) was 0.766 (0.743-0.788) for BMI, $0.772(0.749-0.794)$ for WC and
$0.767(0.745-0.789)$ for WHR. There were no statistically significant differences in the areas under the three curves. 
Table 3 Frequency distribution of cardiovascular risk factors by age and gender; Nizwa survey, 2001

\begin{tabular}{|c|c|c|c|c|c|}
\hline \multirow[b]{2}{*}{ Age group (years) } & \multicolumn{4}{|c|}{ Number of risk factors } & \multirow[b]{2}{*}{ Total (\%) } \\
\hline & None (\%) & One (\%) & Two (\%) & Three (\%) & \\
\hline \multicolumn{6}{|l|}{ Males } \\
\hline $20-29$ & $35(13.6)$ & $136(53.1)$ & $73(28.5)$ & $12(4.7)$ & $256(100)$ \\
\hline 30-39 & $11(7.4)$ & 70 (47.3) & $55(37.1)$ & $12(8.1)$ & $148(100)$ \\
\hline $40-49$ & $8(7.6)$ & 30 (28.3) & 49 (46.2) & 19 (17.9) & $106(100)$ \\
\hline $50-59$ & $5(6.1)$ & $22(26.8)$ & $36(43.9)$ & 19 (23.2) & $82(100)$ \\
\hline $60-69$ & $5(7.3)$ & 13 (19.1) & $28(41.2)$ & 22 (32.4) & $68(100)$ \\
\hline $70+$ & $2(5.6)$ & $11(30.6)$ & $14(38.9)$ & $9(25.0)$ & 36 (100) \\
\hline All & $66(9.5)$ & $282(40.5)$ & $255(36.6)$ & $93(13.4)$ & $696(100)$ \\
\hline \multicolumn{6}{|l|}{ Females } \\
\hline $20-29$ & 67 (23.7) & $184(65.0)$ & $32(11.3)$ & $0(0)$ & $283(100)$ \\
\hline 30-39 & $29(18.5)$ & 93 (59.2) & $32(20.4)$ & $3(1.9)$ & 157 (100) \\
\hline $40-49$ & $12(9.3)$ & $55(42.6)$ & 45 (34.9) & 17 (13.2) & $129(100)$ \\
\hline $50-59$ & $0(0)$ & $25(31.7)$ & $31(39.2)$ & $23(29.1)$ & 79 (100) \\
\hline $60-69$ & $3(6.4)$ & $12(25.5)$ & $16(34.0)$ & $16(34.0)$ & $47(100)$ \\
\hline $70+$ & 1 (3.3) & $9(30.0)$ & 10 (33.3) & 10 (33.3) & $30(100)$ \\
\hline All & $112(15.5)$ & $378(52.1)$ & $166(22.9)$ & $69(9.5)$ & $725(100)$ \\
\hline Total & $178(12.5)$ & 660 (46.5) & $421(29.6)$ & $162(11.4)$ & $1421(100)$ \\
\hline
\end{tabular}

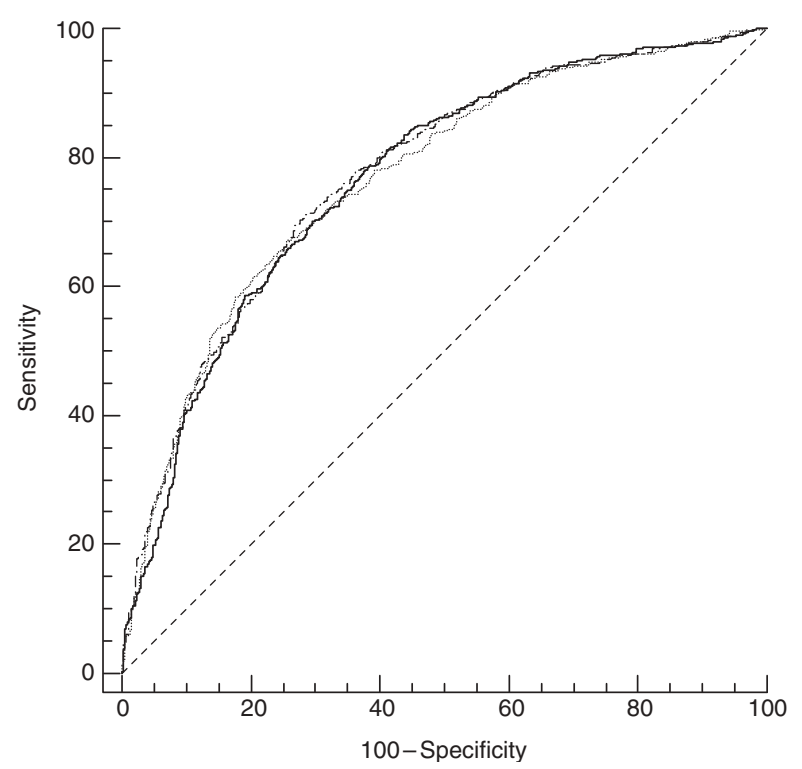

Fig. 1 Receiver-operating characteristic curves depicting body mass index (BMI; - - ), waist circumference (WC; -. -) and waist-to-hip ratio (WHR; ....) in predicting cardiovascular risk. The area under the curve (AUC) (95\% confidence interval) was $0.766(0.743-0.788)$ for BMI, $0.772(0.749-0.794)$ for WC and $0.767(0.745-0.789)$ for WHR. The dashed diagonal reference line $(A \cup C=0.50)$ defines points where a test is no better than chance in identifying individuals with cardiovascular risk

Further ROC plots for each obesity measure against CVD risk depicted optimal gender-specific cut-off points for BMI, WC and WHR together with sensitivity, specificity and area under each curve (Table 4). The cut-off points for BMI and WC in men $\left(23.2 \mathrm{~kg} \mathrm{~m}^{-2}\right.$ and $80 \mathrm{~cm}$, respectively) were lower than in women $\left(26.8 \mathrm{~kg} \mathrm{~m}^{-2}\right.$ and $84.5 \mathrm{~cm}$, respectively); while the cut-off points for WHR were identical for both genders (0.91 for both). Comparing the effects of the cut-off points recommended by the $\mathrm{WHO} / \mathrm{IDF}^{6}$ with those estimated from the ROC curves, the prevalence of obesity among men assessed by BMI increased from about $41 \%$ to nearly $60 \%$. The impact on central obesity (WC) among men was even greater, resulting in an increase from about 16\% to nearly 50\% (Table 5). On the other hand, the prevalence of obesity among women was reduced when measured by any one of the three indices.

\section{Discussion}

This is the first population-based study to benchmark gender-specific cut-off points for BMI, WC and WHR for Omani Arabs based on current levels of CVD risk factors. The derived cut-off points provide valid and non-arbitrary values to assess overall obesity and central adiposity among Arab ethnic groups.

The WHO recommends the use of pre-specified cut-off points for BMI, WC and WHR to standardise comparisons within and between populations ${ }^{1}$. Currently such cut-off points are derived from studies among European populations and thus may not be applicable to other ethnic groups. Indeed, some studies suggested that Asian populations manifest CVD risk factors at lower levels of $\mathrm{BMI}$ and WC than Westerners, owing, in part, to a higher percentage of body fat ${ }^{5,9,10}$.

Based on sensitivity, specificity and ROC curve analysis, BMI values of $>23.2$ and $>26.8 \mathrm{~kg} \mathrm{~m}^{-2}$, WC of $>80$ and $>84.5 \mathrm{~cm}$ and WHR of $>0.91$ (both sexes) appear to best characterise high CVD risk among Omani men and women, respectively. The suggested cut-off points are consistent with figures reported in other studies from 
Table 4 Optimal cut-off points for defining obesity using three anthropometric variables - body mass index (BMI), waist circumference (WC) and waist-to-hip ratio (WHR) - in relation to cardiovascular risk and gender, with associated sensitivity (\%), specificity (\%) and area under the curve (AUC) among Omani Arabs

\begin{tabular}{lccrr}
\hline & Cut-off point & Sensitivity $(95 \% \mathrm{Cl})$ & Specificity $(95 \% \mathrm{Cl})$ & $\mathrm{AUC}(95 \% \mathrm{Cl})$ \\
\hline BMI $\left(\mathrm{kg} \mathrm{m}^{-2}\right)$ & & & & \\
$\quad$ Males & 23.2 & $71.0(65.9-75.7)$ & $53.7(48.3-59.1)$ & $0.65(0.61-0.68)$ \\
$\quad$ Females & 26.8 & $46.8(40.3-53.4)$ & $76.5(72.5-80.2)$ & $0.66(0.62-0.69)$ \\
WC (cm) & 80.0 & $65.2(60.0-70.2)$ & $66.7(61.4-71.6)$ & $0.70(0.66-0.73)$ \\
$\quad$ Males & 84.5 & $71.9(65.7-77.6)$ & $61.6(57.2-66.0)$ & $0.71(0.68-0.74)$ \\
$\quad$ Females & 0.91 & $58.0(52.7-63.3)$ & $71.6(66.5-76.2)$ & $0.68(0.65-0.72)$ \\
WHR & 0.91 & $67.2(60.8-73.2)$ & $73.7(69.5-77.5)$ & $0.76(0.73-0.79)$ \\
$\quad$ Males & & & & \\
$\quad$ Females & & & &
\end{tabular}

$\mathrm{Cl}$ - confidence interval.

Total men $=695$ and women $=725$.

Table 5 Comparison of prevalence of obesity (\%) using cut-off points recommended by the by World Health Organization (WHO)/ International Diabetes Federation (IDF) and cut-off points from analysis of receiver-operating characteristic (ROC) curves; Nizwa survey, 2001

\begin{tabular}{lccccc}
\hline & \multicolumn{2}{c}{ Males } & & \multicolumn{2}{c}{ Females } \\
\cline { 2 - 3 } \cline { 5 - 6 } & WHO/IDF & ROC curves & & WHO/IDF & ROC curves \\
\hline BMI & 41.4 & 58.9 & & 42.1 & 31.6 \\
WC & 16.4 & 49.3 & & 60.6 & 49.2 \\
WHR & 46.5 & 43.5 & & 58.4 & 39.7 \\
\hline
\end{tabular}

$\mathrm{BMI}$ - body mass index; WC - waist circumference; WHR - waist-to-hip ratio.

Asia. For example, BMI of $\geq 24 \mathrm{~kg} \mathrm{~m}^{-1}$ in China ${ }^{11}$, $\geq 25 \mathrm{~kg} \mathrm{~m}^{-2}$ in Japan $^{4}$ and $27 \mathrm{~kg} \mathrm{~m}^{-2}$ in Indonesia ${ }^{12}$ was found to categorise obese individuals best in relation to high prevalent CVD risk. Similarly, the reported cut-off points for WC range from $102 \mathrm{~cm}$ for American men ${ }^{13}$, to $94 \mathrm{~cm}$ for Europeans, $90 \mathrm{~cm}$ for Chinese and other Asians $^{6}$, to $85 \mathrm{~cm}$ for Tunisians ${ }^{14}$ and Japanese ${ }^{6}$. The corresponding figures among women are $88 \mathrm{~cm}$ for Americans $^{13}$, $80 \mathrm{~cm}$ for Europeans, Chinese and Asians ${ }^{6}$, $85 \mathrm{~cm}$ for Tunisians ${ }^{14}$ and $90 \mathrm{~cm}$ for Japanese ${ }^{6}$.

Differences in cut-off points of obesity have a profound effect on prevalence estimates. In comparison with the cut-off points derived via analysis of ROC curves, the current $\mathrm{WHO}^{1}$ and $\mathrm{IDF}^{6}$ cut-off points underestimate overall obesity by over $42 \%$ and central adiposity by two times among men. This appears to be due to more stringent ROC curve-determined cut-off points. On the other hand, the prevalence of overall and central obesity is underestimated among women when ROC curvedepicted cut-off points are applied compared with WHOand IDF-suggested cut-off points.

Our analysis also showed almost equal area under the ROC curves for BMI, WC and WHR. Thus any one of the three indices could be used either in clinical practice or epidemiological research as proxy to assess subjects' body fat. An earlier study, almost a decade ago, found all three indices of obesity to be strongly and independently associated with the risk of type 2 diabetes mellitus among Omanis, with WC being the strongest predictor ${ }^{15}$. Studies among other populations showed that WC alone ${ }^{16,17}$ or together with $\mathrm{BMI}^{18}$ is a good predictor for CVD risk and type 2 diabetes mellitus. We feel that measurement of WC is a simpler method to assess body fat and requires a single step to measure (by using a tailor's tape). In contrast, BMI requires two separate measurements (weight and height) and availability of a scale and a stadiometer.

This study illustrates a high distribution of CVD risk factors among Omani Arabs. Less than four decades ago, this population was living in harsh desert conditions, mostly as Bedouin nomads, with infectious diseases as the dominant feature of their ill-health. Today, more than a quarter of the population appears to have established CVD risk factors such as hypertension or dyslipidaemia, and at least one in 10 adults suffers from type 2 diabetes mellitus. This may be attributed to the rapid epidemiological transition sweeping developing countries, such as Oman, as a result of demographic, socio-economic, technological, cultural, environmental and biological changes $^{19}$. The contribution of genetic components to the high CVD risk factor prevalence in this population is not clear, but is likely to be high, in view of the high prevalence of risk factors such as dyslipidaemia.

Given the continuous increase in the trend of obesity and CVD risk factors witnessed by the domination of non-communicable diseases over the global burden of diseases in developed and developing countries ${ }^{20}$, determining an individual's obesity status becomes vital for monitoring, prevention and possible treatment purposes. This is particularly relevant when it is coupled with assessment of the individual's CVD risk. Thus we encourage use of the determined cut-off points by health workers in both clinical and public health practice in Oman. To increase the utility of the determined cut-off points we also recommend that fractions to be approximated to the nearest integer.

The differences in the suggested cut-off points for BMI, WC and WHR reported in different Asian studies may reflect the differences in decisions regarding the 
definition of what constitutes prevalent 'CVD risk'. Like an earlier study ${ }^{19}$ among a Chinese population, the current study adopted the presence of 'two or more' risk factor to characterise individuals as having CVD risk. If a different decision was adopted (all three risk factors for example), then different cut-off points would have been obtained. In addition, variation in the definition could have also led to different results. For example, diabetes could be defined according to fasting levels of glucose, or by 2 -h post-load glucose in the 75-g OGTT, or a combination of the two. Alternatively, the differences may reflect real underlying differences in body fat percentages corresponding to a given BMI, WC or WHR value between Arabs compared with Asians or European ethnic groups. Thus the proposed cut-off points need to be validated in other Arab populations in the Middle East.

While it is useful to have ethnic-specific cut-off points for various obesity indices, the suggested values in this study will result in an increase in the prevalence of obesity by at least three to four times among Omani males, regardless to which indicator (BMI, WC or WHR) is used (Table 4). This could have serious financial bearings on the national health budget in Oman, if obesity treatment is to be provided, like other services, free of charge. It has also been shown that treatment of obesity is difficult: even when using the best treatments, the effect is relatively small. Therefore, prevention of obesity needs to have particular emphasis particularly among the young.

Our study has a few limitations. First, it relates the risk of CVD to BMI, WC and WHR in a cross-sectional setting using the occurrence of established risk factors as a proxy risk estimate. This indicates the need for prospective studies that relate anthropometric measures to the incidence of diabetes, hypertension, dyslipidaemia and clinical CVD mortality and all-cause mortality. In addition, to address inconsistencies in cut-off points seen between different Asian populations, such studies must include various Arab groups of the Middle East using comparative and tested methodologies.

Second, our study did not use direct methods to measure body fatness in relation to CVD risk factors and relied mainly on surrogates for overall obesity (BMI) or abdominal obesity (WC and WHR). Future studies may need to consider body fatness and body fat distribution and their relationship with the surrogate anthropometric indices. However, currently available direct measures of body fatness are fairly expensive and complicated, and may not be useful for large population-based studies.

We conclude that there is a high distribution of CVD risk factors among Omanis. The cut-off points for BMI and WC are lower for males and higher for females than those currently used. We encourage the use of these cut-off points when considering classifying Omani individuals in relation to their obesity status. Prospective studies are needed to assess the relationship of different obesity surrogates to CVD morbidity and mortality.

\section{Acknowledgements}

Sources of funding: The Nizwa project was funded jointly by the Ministry of Health of Oman and the WHO Eastern Mediterranean Regional Office.

Conflict of interest declaration: The authors have no conflict of interest to declare.

Authorship responsibilities: J.A.A. wrote the protocol of the study, performed all data analysis and wrote the manuscript. P.J. refined the study protocol, trained field staff and provided significant advice and consultation on the manuscript.

Acknowledgements: We would like to thank Mr Khalid Saleem for his technical support during this study and Dr Medhat K El-Sayyed for his statistical advice, both of whom gave approval to be acknowledged.

\section{References}

1 World Health Organization (WHO). Obesity: Preventing and Managing the Global Epidemic. WHO Technical Report Series No. 894. Geneva: WHO, 2000.

2 World Health Organization (WHO). Definition, Diagnosis and Classification of Diabetes Mellitus and Its Complications. Part 1: Diagnosis and Classification of Diabetes Mellitus. Provisional Report of a WHO Consultation. Geneva: WHO, 1999.

3 World Health Organization, Regional Office for the Western Pacific/International Association for the Study of Obesity/ International Obesity Task Force. The Asia Pacific Perspective: Redefining Obesity and Its Treatment. St Leonards, Australia: Health Communications Australia Pty Limited, 2000: $22-9$.

4 Kanazawa M, Yoshiike N, Osaka T, Numba Y, Zimmet P, Inoue S. Criteria and classification of obesity in Japan and Asia-Oceania. Asia Pacific Journal of Clinical Nutrition 2002; 11(Suppl. 8): S732-7.

5 Deurenberg-Yap M, Yian TB, Kai CS, Deurenberg P, van Staveren WA. Manifestation of cardiovascular risk factors at low levels of body mass index and waist-to-hip ratio in Singaporean Chinese. Asia Pacific Journal of Clinical Nutrition 1999; 8: 177-83.

6 Alberti KG, Zimmet P, Shaw J. Metabolic syndrome - a new world-wide definition. A consensus statement from the International Diabetes Federation. Diabetic Medicine 2006; 23: 469-80.

7 Al-Lawati JA, Mohammed AJ, Al-Hinai HQ, Jousilahti P. Prevalence of the metabolic syndrome among Omani adults. Diabetes Care 2003; 26: 1781-5.

8 Alberti KG, Zimmet PZ. Definition, diagnosis and classification of diabetes mellitus and its complications. Part 1: diagnosis and classification of diabetes mellitus provisional report of a WHO consultation. Diabetic Medicine 1998; 15: 539-53.

9 He M, Tan KC, Li ET, Kung AW. Body fat determination by dual energy X-ray absorptiometry and its relation to body mass index and waist circumference in Hong Kong Chinese. International Journal of Obesity and Related Metabolic Disorders 2001; 25: 748-52.

10 Chang CJ, Wu CH, Chang CS, Yao WJ, Yang YC, Wu JS, et al. Low body mass index but high percent body fat in Taiwanese subjects: implications of obesity cutoffs. International Journal of Obesity and Related Metabolic Disorders 2003; 27: 253-9.

11 Wildman RP, Gu D, Reynolds K, Duan X, He J. Appropriate body mass index and waist circumference cutoffs for 
categorization of overweight and central adiposity among Chinese adults. American Journal of Clinical Nutrition 2004; 80: 1129-36.

12 Gurrici S, Hartriyanti Y, Hautvast JG, Deurenberg P. Relationship between body fat and body mass index: differences between Indonesians and Dutch Caucasians. European Journal of Clinical Nutrition 1998; 52: 779-83.

13 National Institutes of Health (NIH). Third Report of the National Cholesterol Education Program (NCEP) Expert Panel on Detection, Evaluation, and Treatment of High Blood Cholesterol in Adults (Adult Treatment Panel III). Bethesda, MD: NIH, 2001; Chapter 2.

14 Bouguerra R, Alberti H, Smida H, Salem LB, Rayana CB, El Atti J, et al. Waist circumference cut-off points for identification of abdominal obesity among the Tunisian adult population. Diabetes, Obesity and Metabolism (OnlineEarly Articles); doi:10.1111/j.1463-1326.2006.00667.x.

15 Al-Asfoor DH, Al-Lawati JA, Mohammed AJ. Body fat distribution and the risk of non-insulin-dependent diabetes mellitus in the Omani population. Eastern Mediterranean Health Journal 1999; 5: 14-20.
16 Reeder BA, Senthilselvan A, Despres JP, Angel A, Liu L, Wang $\mathrm{H}$, et al. The association of cardiovascular disease risk factors with abdominal obesity in Canada. Canadian Heart Health Surveys Research Group. Canadian Medical Association Journal 1997; 157(Suppl. 1): S39-45.

17 Pouliot MC, Despres JP, Lemieux S, Moorjani S, Bouchard C, Tremblay A, et al. Waist circumference and abdominal sagittal diameter: best simple anthropometric indexes of abdominal visceral adipose tissue accumulation and related cardiovascular risk in men and women. American Journal of Cardiology 1994; 73: 460-8.

18 Wang Y, Rimm EB, Stampfer MJ, Willett WC, Hu FB. Comparison of abdominal adiposity and overall obesity in predicting risk of type 2 diabetes among men. American Journal of Clinical Nutrition 2005; 81: 555-63.

19 Wahdan MH. The epidemiological transition. Eastern Mediterranean Health Journal 1996; 2: 8-20.

20 World Health Organization (WHO). The World Health Report 2002: Reducing Risks, Promoting Healthy Life. Geneva: WHO, 2002. 